\title{
Restrictive ventilatory impairment is associated with poor outcome in patients with cT1aNOMO peripheral squamous cell carcinoma of the lung
}

\author{
Hiroyuki Tao ${ }^{1}$, Junichi Soh ${ }^{2}$, Hiromasa Yamamoto ${ }^{2}$, Toshiya Fujiwara ${ }^{3}$, Tsuyoshi Ueno ${ }^{4}$, Makio Hayama ${ }^{5}$, \\ Mikio Okazaki ${ }^{6}$, Ryujiro Sugimoto ${ }^{4,7}$, Motohiro Yamashita ${ }^{4}$, Yoshifumi Sano ${ }^{6}$, Kazunori Okabe ${ }^{1}$, Motoki \\ Matsuura $^{3}$, Kazuhiko Kataoka ${ }^{7}$, Shigeharu Moriyama ${ }^{5}$, Shinichi Toyooka ${ }^{2,8}$, Shinichiro Miyoshi ${ }^{2}$ \\ ${ }^{1}$ Division of Thoracic Surgery, National Hospital Organization Yamaguchi-Ube Medical Center, Ube, Japan; ${ }^{2}$ Department of Thoracic Surgery, \\ Okayama University Hospital, Okayama, Japan; ${ }^{3}$ Department of Thoracic Surgery, Hiroshima City Hospital, Hiroshima, Japan; ${ }^{4}$ Department of \\ Thoracic Surgery, National Hospital Organization Shikoku Cancer Center, Matsuyama, Japan; ${ }^{5}$ Department of Thoracic Surgery, Okayama Red \\ Cross General Hospital, Okayama, Japan; ${ }^{6}$ Center of Chest Medicine and Surgery, Ehime University, Toon, Japan; ${ }^{7}$ Department of Thoracic Surgery, \\ National Hospital Organization Iwakuni Clinical Center, Iwakuni, Japan; ${ }^{8}$ Department of Clinical Genomic Medicine, Okayama University Hospital, \\ Okayama, Japan \\ Contributions: (I) Conception and design: H Tao, J Soh, H Yamamoto, T Ueno, R Sugimoto, M Okazaki, M Hayama, T Fujiwara, S Toyooka; (II) \\ Administrative support: M Yamashita, Y Sano, K Okabe, M Matsuura, K Kataoka, S Moriyama, S Miyoshi; (III) Provision of study materials or \\ patients: H Tao, J Soh, H Yamamoto; (IV) Collection and assembly of data: H Tao, J Soh, H Yamamoto, T Ueno, R Sugimoto, M Okazaki, M \\ Hayama, T Fujiwara; (V) Data analysis and interpretation: H Tao, J Soh, H Yamamoto, S Toyooka; (VI) Manuscript writing: All authors; (VII) Final \\ approval of manuscript: All authors. \\ Correspondence to: Hiroyuki Tao. Division of Thoracic Surgery, National Hospital Organization Yamaguchi-Ube Medical Center, 685 Higashi-kiwa, \\ Ube 755-0241, Japan. Email: htao@yamaguchi-hosp.jp.
}

Background: Patients with squamous cell carcinoma ( $\mathrm{SqCC}$ ) of the lung sometimes have a comorbid pulmonary disease such as pulmonary emphysema or an interstitial lung disease (ILD), both of which negatively affect patient outcome. The aim of this study was to determine the outcome of patients in a multicenter database who underwent surgery for cT1aN0M0 peripheral SqCC lung cancer.

Methods: The medical records of a total of 228 eligible patients from seven institutions were reviewed to evaluate the impact of concomitant impaired pulmonary function and other clinicopathological factors on overall survival (OS) and relapse-free survival (RFS).

Results: Six patients with positive or unclear tumor margins were excluded. Of the 222 remaining study patients, $42(18.9 \%)$ and $97(43.7 \%)$ patients were found to have coexisting restrictive or obstructive ventilatory impairment, respectively. Over a median follow-up period of 30.6 months, the 5 -year OS and RFS were $69.0 \%$ and $62.6 \%$, respectively. By multivariate analysis, ILDs identified on high-resolution computed tomography (HRCT), pulmonary function test results indicating a restrictive ventilatory impairment, and wedge resection were found to be independent risk factors for poor OS. An increased level of serum squamous cell carcinoma antigen (SCC-Ag) $(>1.5 \mathrm{ng} / \mathrm{mL})$ and the same risk factors for poor OS were independent risk factors for recurrence. Among patients who underwent anatomical lung resection (lobectomy and segmentectomy, $\mathrm{n}=173$ ), a restrictive ventilatory impairment was an independent risk factor for poor OS, and increased serum SCC-Ag level, ILDs on HRCT, and restrictive ventilatory impairment were independent risk factors for poor RFS by multivariate analysis. Factors such as visceral pleural invasion, and lymphatic or vascular invasion were not significantly associated with outcome.

Conclusions: A restrictive ventilatory impairment negatively affects the outcome of patients with cT1aN0M0 peripheral SqCC lung cancer.

Keywords: Squamous cell carcinoma of the lung; interstitial lung disease (ILD); restrictive ventilatory impairment 
Submitted Dec 20, 2016. Accepted for publication Jul 28, 2017.

doi: $10.21037 /$ jtd.2017.10.70

View this article at: http://dx.doi.org/10.21037/jtd.2017.10.70

\section{Introduction}

The use of computed tomography (CT) has increased the detection rates of peripheral small non-small cell lung cancers (NSCLCs), the majority of which are adenocarcinomas (1). Patients with these tumors who undergo complete surgical resection are expected to have favorable outcomes (2). Several retrospective (3-5) and prospective $(6,7)$ studies have reported that segmentectomy as an intentional limited resection for patients with early-stage peripheral NSCLC is both oncologically and physiologically beneficial. Squamous cell carcinoma (SqCC) of the lung is the second most common histological subtype of NSCLC after adenocarcinoma. Although both are categorized as NSCLC, lung adenocarcinoma and SqCC manifest different clinical behaviors and outcomes $(8,9)$. For example, lymphatic and vascular invasion predict different outcomes in patients with pathologic stage I lung adenocarcinoma $v s$. pathologic stage I lung SqCC (9). The number of peripheral small lung SqCCs being detected has also increased $(10,11)$; however, the reported prevalence of lung $\mathrm{SqCC}$ is low, ranging from $8 \%$ to $17 \%$ of cT1aN0M0 peripheral NSCLCs $(12,13)$.

In addition to the intrinsic characteristics of lung cancers that indicate biological aggressiveness, a background of pulmonary disease negatively affects patient outcome $(14,15)$. Pulmonary emphysema and interstitial lung diseases (ILDs) are major pulmonary comorbidities that are sometimes seen in patients with lung cancer. Cigarette smoking is a well-established cause of both chronic obstructive pulmonary disease (COPD) and lung cancer, and lung SqCC is strongly associated with smoking (16). ILDs have also been found to be associated with an increased risk of lung cancer $(17,18)$. The prevalence of lung SqCC is increased in patients with ILDs $(19,20)$. Therefore, patients with lung SqCC are more likely to have comorbid pulmonary diseases and impaired pulmonary function.

In this study, we retrospectively reviewed the records from a multicenter database of patients with cT1aN0M0 peripheral lung SqCC who underwent surgery with the aim of evaluating the prognostic impact of relevant clinicopathological factors, including pulmonary function parameters. Since wedge resection even for this clinical tumor stage is considered to be palliative and not curative, we also analyzed the background of patients who underwent wedge resection. Finally, we sought to clarify the outcome of patients who underwent anatomical resection.

\section{Methods}

\section{Study population}

This study was approved by the ethics board of each institution. The requirement for informed consent was waived because of the retrospective nature of the study. The medical records of a total of 228 patients with cT1aN0M0 peripheral SqCC of the lung who underwent surgery from September 2002 to November 2014 at seven institutions were reviewed retrospectively. Patients were followed at each institution by routine physical and blood examinations and chest or systemic CT scan with or without enhancement every 6 months for the first 2 years, and then plain CT annually. Peripheral tumor was defined as that located within the peripheral two-thirds of the lung parenchyma on CT (21). Tumor-node-metastasis classification stages were revised according to the Seventh Edition of the TNM classification. Patients with lung SqCCs in the tracheobronchial tree and patients with metastatic tumors to the lung were not included in the analysis. Patients who received pre-operative chemotherapy or radiotherapy were excluded. Six patients with positive or unclear tumor margins were excluded from the study, leaving a total of 222 patients for analysis.

\section{Data collection}

The following information was collected: age, gender, pulmonary function, tumor location, tumor diameter on high-resolution computed tomography (HRCT) (including size of areas of consolidation), preoperative serum levels of tumor markers [carcinoembryonic antigen (CEA), squamous cell carcinoma antigen (SCC-Ag), and cytokeratin-19 fragments (CYFRA 21-1)], coexisting radiological ILD on HRCT, operative procedure, pathological nodal status, presence/absence of visceral pleural invasion, lymphatic invasion, and vascular invasion. ILD was evaluated by experienced radiologists in chest CT interpretation at each institution, in accordance with the ATS/ERS/Japanese 
Respiratory Society/Latin American Thoracic Association Statement (22). Restrictive and obstructive ventilatory impairment were defined as reduced vital capacity of $<80 \%$ of predicted, and as a ratio of forced expiratory volume in 1 second to forced vital capacity of $<70 \%$, respectively. Overall survival (OS) was defined as the time interval from date of operation until date of death or last follow up. Relapse-free survival (RFS) was defined as the time interval from date of operation to date of proven detection of recurrence or metastases. Local relapse was defined as recurrent disease at the primary site or in the lymph nodes either in the hilum or mediastinum within the operated thoracic cavity (7).

\section{Statistical analyses}

The relationships between the operative procedures (wedge $v s$. anatomical resection) and clinical factors were analyzed using the chi-square test of independence. The two-sample Student $t$-test was used for continuous variables. The impact of clinicopathological factors on OS and RFS was evaluated by Kaplan-Meier analysis and the log-rank test with $95 \%$ confidence intervals (CIs). The Cox proportional hazard regression model was also employed to assess risk factors for survival. All tests of significance were two-sided, and $\mathrm{P}$ values less than 0.05 were considered statistically significant. Statistical analysis was performed using SPSS software (version 23; IBM SPSS, Chicago, IL, USA).

\section{Results}

\section{Patient characteristics}

Patient characteristics $(\mathrm{N}=222)$ are shown in Table 1. The mean diameters of tumors and areas of consolidation were 15.4 [5-20] and 15.3 [5-20] mm, respectively. The consolidation/tumor ratios ranged from $55.6 \%$ to $100 \%$, and $218(98.2 \%)$ of all the tumors appeared as pure solid nodules. Coexisting restrictive and obstructive lung disease on pulmonary function testing was seen in $42(18.9 \%)$ and 97 (43.7\%) patients, respectively. Wedge resection was more often conducted for patients who were older, with smaller tumors, and reduced vital capacity. More patients with tumors located in lower pulmonary lobes, ILDs on HRCT, and obstructive pulmonary disease underwent wedge resection, although the data were not statistically significant (Table 2).

\section{Overall outcomes}

The 5-year OS and RFS were $69.0 \%$ and $62.6 \%$, respectively [median follow-up period: 30.6 (range, 1-144) months]. Univariate analysis revealed that increased serum level of SCC-Ag, that of CYFRA 21-1, ILDs on HRCT, restrictive ventilatory impairment, and wedge resection were significant risk factors for both poor OS and RFS (data not shown). Multivariate analysis revealed that ILDs on HRCT [hazard ratio (HR) $(95 \% \mathrm{CI})=2.16(1.15-4.06)$, $\mathrm{P}=0.017]$, restrictive ventilator defect $[\mathrm{HR}(95 \% \mathrm{CI})=2.97$ (1.57-5.59), $\mathrm{P}=0.001$ ], and wedge resection [HR (95\% $\mathrm{CI})=2.03(1.06-3.89), \mathrm{P}=0.034]$ were independent risk factors for poor OS. An increased level of serum SCC-Ag $(>1.5 \mathrm{ng} / \mathrm{mL})[\mathrm{HR}(95 \% \mathrm{CI})=1.71(1.00-2.91), \mathrm{P}=0.034]$ and the same risk factors for poor OS [ILDs on HRCT; HR $(95 \% \mathrm{CI})=2.65(1.52-4.63), \mathrm{P}=0.001$, restrictive ventilator defect; HR $(95 \%$ CI $)=2.35$ (1.31-4.22), $\mathrm{P}=0.004$, wedge resection; HR $(95 \% \mathrm{CI})=2.85(1.61-5.05), \mathrm{P}<0.001]$ were independent risk factors for recurrence.

\section{Outcome of patients undergoing anatomical resection}

We then further evaluated the patients who underwent anatomical lung resection (segmentectomy and lobectomy, $n=173$ ). The characteristics of these patients are shown in Table 3. The mean tumor diameter was 15.5 [5-20] $\mathrm{mm}$. The 5-year OS and RFS were $77.5 \%$ and $69.8 \%$, respectively. Univariate analysis revealed that increased serum level of SCC-Ag and restrictive ventilatory impairment (Figure 1A) were significant risk factors for poor OS. Increased serum level of SCC-Ag, ILDs on HRCT, and restrictive ventilatory impairment (Figure 1B) were significant risk factors for recurrence (Table 4). Multivariate analysis revealed that restrictive ventilatory impairment was an independent risk factor for OS, and increased serum level of SCC-Ag, ILDs on HRCT, and restrictive ventilatory impairment were independent risk factors for RFS (Table 5).

During the median follow-up period of 32.6 [1-144] months, local recurrence was detected in 5 (2.9\%) of 173 patients who underwent anatomical resection, as follows: among patients undergoing segmentectomy, 1 patient developed subcarinal lymph node metastasis and 1 patient developed malignant pleural effusion; among patients undergoing lobectomy, 1 patient developed pleural dissemination and 2 patients developed lymph node metastasis in lymphatic drainage areas. 
Table 1 Clinicopathological characteristics of all patients

\begin{tabular}{|c|c|}
\hline Characteristics & No. (\%) \\
\hline Total cases & 222 \\
\hline Age, y (mean \pm standard deviation) & $72.0 \pm 7.7$ \\
\hline$>70$ & $136(61.3)$ \\
\hline \multicolumn{2}{|l|}{ Gender } \\
\hline Male & $189(85.1)$ \\
\hline \multicolumn{2}{|l|}{ Smoking status } \\
\hline Current & $70(31.5)$ \\
\hline Former & $147(66.2)$ \\
\hline Never & $5(2.3)$ \\
\hline \multicolumn{2}{|l|}{ Tumor location } \\
\hline Right upper lobe & $57(25.7)$ \\
\hline Right middle lobe & $6(2.7)$ \\
\hline Right lower lobe & $63(28.4)$ \\
\hline Left upper lobe & $49(22.1)$ \\
\hline Left lower lobe & $47(21.2)$ \\
\hline \multicolumn{2}{|l|}{ Serum CEA $(\mathrm{ng} / \mathrm{mL})^{\star 1}$} \\
\hline$\leq 5.0$ & $153(76.5)$ \\
\hline$>5.0$ & $47(23.5)$ \\
\hline \multicolumn{2}{|l|}{ Serum SCC-Ag (ng/mL) ${ }^{\star 2}$} \\
\hline$\leq 1.5$ & $111(74.0)$ \\
\hline$>1.5$ & $39(26.0)$ \\
\hline \multicolumn{2}{|l|}{ Serum CYFRA $21-1(\mathrm{ng} / \mathrm{mL})^{\star 3}$} \\
\hline$\leq 3.5$ & $151(81.2)$ \\
\hline$>3.5$ & $35(18.8)$ \\
\hline \multicolumn{2}{|l|}{ ILDs on HRCT } \\
\hline Yes & $44(19.8)$ \\
\hline \multicolumn{2}{|l|}{$\% \mathrm{VC}$} \\
\hline$<80$ & $42(18.9)$ \\
\hline \multicolumn{2}{|l|}{$\mathrm{FEV}_{1.0} \%$} \\
\hline$<70$ & $97(43.7)$ \\
\hline \multicolumn{2}{|l|}{ Operation } \\
\hline Wedge resection & $49(22.1)$ \\
\hline Segmentectomy & 47 (21.2) \\
\hline Lobectomy & $126(56.8)$ \\
\hline
\end{tabular}

Table 1 (continued)
Table 1 (continued)

\begin{tabular}{lc}
\hline Characteristics & No. (\%) \\
\hline Pathological nodal involvement & \\
pNX & $49(22.1)$ \\
pN0 & $167(75.2)$ \\
pN1 & $4(1.8)$ \\
pN2 & $2(0.9)$
\end{tabular}

Pathological stage

IA

$143(64.4)$

IB

25 (11.3)

IIA

$3(1.3)$

IIIA

Unclear

$49(22.1)$

Visceral pleural invasion

PLO

$192(87.3)$

PL1

$28(8.5)$

PL2

Lymphatic invasion

Ly0

152 (68.5)

Ly1

$70(31.5)$

Vascular invasion

vo

156 (70.3)

V1

60 (27.0)

V2

$6(2.7)$

${ }^{* 1}$, serum CEA was measured in 200 patients; ${ }^{* 2}$, serum SCCAg was measured in 150 patients; ${ }^{* 3}$, serum CYFRA 21-1 was measured in 186 patients. CEA, carcinoembryonic antigen; SCC-Ag, squamous cell carcinoma antigen; CYFRA 21-1, cytokeratin-19 fragments; ILD, interstitial lung disease; HRCT, high-resolution computed tomography.

\section{Discussion}

In this study, we found that the coexisting restrictive ventilatory impairment was an independent risk factor for unfavorable outcomes in patients undergoing surgery for cT1aN0M0 peripheral SqCC of the lung. Visceral pleural invasion, lymphatic invasion, and vascular invasion, which are known to be unfavorable prognostic indicators for small NSCLCs, were not found to be significant prognostic 
Table 2 Operative procedures

\begin{tabular}{|c|c|c|c|}
\hline Variable & \multicolumn{2}{|c|}{ Procedure } & $P$ value \\
\hline Age (years) & $76.1 \pm 6.7$ & $71.5 \pm 7.7$ & $<0.001$ \\
\hline \multicolumn{4}{|l|}{ Gender } \\
\hline Female & $8(24.2)$ & $25(75.8)$ & 0.745 \\
\hline \multicolumn{4}{|l|}{ Tumor location } \\
\hline Lower lobe & $30(27.3)$ & $80(72.7)$ & 0.064 \\
\hline Other than lower lobe & $19(17.0)$ & $93(83.0)$ & \\
\hline Tumor size (mm) & $12.1 \pm 6.6$ & $15.0 \pm 4.1$ & 0.004 \\
\hline \multicolumn{4}{|l|}{ ILDs on HRCT } \\
\hline No & $35(19.7)$ & $143(80.3)$ & \\
\hline$\% \mathrm{VC}$ & $85.2 \pm 20.9$ & $99.7 \pm 18.1$ & $<0.001$ \\
\hline FEV $_{1.0} \%$ & $66.9 \pm 16.3$ & $71.0 \pm 11.5$ & 0.106 \\
\hline
\end{tabular}

ILD, Interstitial lung disease; HRCT, high-resolution computed tomography; VC, vital capacity; FEV $_{1.0}$, forced expiratory volume in $1 \mathrm{~s}$.

indicators in this study.

Among all the study patients, wedge resection was found to be an independent risk factor for both poor OS and RFS. Because the tumors of all the patients in this study manifested solid-dominant or pure-solid appearance on HRCT, we surmise that wedge resection was mainly performed because of the poor condition of the patients, although the reasons for the limited resections were unavailable. However, the procedure was more frequently performed for older patients and those with restrictive ventilatory impairment in this study. Veluswamy and colleagues (23) reported that neither wedge resection nor segmentectomy were equivalent to lobectomy for OS or lung-cancer-specific survival in patients older than 65 years with cT1aN0M0 SqCC of the lung, and concluded that lobectomy should be considered for patients with such tumors. Our results also showed worse outcomes for patients undergoing segmentectomy compared to those undergoing lobectomy, although the results were not statistically significant. Patients with early-stage peripheral lung SqCCs and impaired lung function would more likely receive limited resection; however, lobectomy should be the procedure of choice for patients who are thought sufficiently able to tolerate the procedure.

Lung cancer patients with comorbid ILD have been found to have worse survival than patients without ILD $(19,24,25)$. Sato and colleagues (26) analyzed the surgical outcomes of patients with NSCLC and ILDs who were in a nation-wide database and found that the 5-year OS of patients with stage IA NSCLC and restrictive ventilatory impairment was, surprisingly, as poor as $20 \%$. Our study found radiological evidence of ILDs in almost $20 \%$ of patients, and these patients tended to have decreased vital capacity (data not shown). Considering that radiological ILDs could include non-progressive diseases that would exert minimal effect on survival, pulmonary function tests that provide evidence of restrictive ventilatory impairment should reasonably be more predictive of outcome than radiological evidence of ILDs, although their influence upon tumor progression is unknown.

Since cigarette smoking is strongly associated with the development of lung SqCC (16) and emphysema, patients with lung SqCC often have coexisting emphysema. The negative prognostic impact of emphysema on patients with lung cancer has been shown in several studies (27); however, whether or not coexisting emphysema affects the outcome of patients with early-stage lung SqCC remains unclear. A meta-analysis found a strong association between COPD and worse OS in patients with early-stage lung cancer (27). On the other hand, Lee and colleagues (28) 
Table 3 Clinicopathological characteristics of the patients who received anatomical resection

\begin{tabular}{|c|c|}
\hline Characteristics & No. (\%) \\
\hline Total cases & 173 \\
\hline Age, y (mean \pm standard deviation) & $71.5 \pm 7.7$ \\
\hline$>70$ & $97(56.1)$ \\
\hline \multicolumn{2}{|l|}{ Gender } \\
\hline Male & $148(85.5)$ \\
\hline \multicolumn{2}{|l|}{ Smoking status } \\
\hline Current & $60(34.7)$ \\
\hline Former & $109(63.0)$ \\
\hline Never & $4(2.3)$ \\
\hline \multicolumn{2}{|l|}{ Tumor location } \\
\hline Right upper lobe & $44(25.4)$ \\
\hline Right middle lobe & $6(3.4)$ \\
\hline Right lower lobe & $43(24.9)$ \\
\hline Left upper lobe & $43(24.9)$ \\
\hline Left lower lobe & $37(21.4)$ \\
\hline \multicolumn{2}{|l|}{ Serum CEA $(n g / m L)^{\star 1}$} \\
\hline$\leq 5.0$ & $121(77.6)$ \\
\hline$>5.0$ & $35(22.4)$ \\
\hline \multicolumn{2}{|l|}{ Serum SCC-Ag $(n g / m L)^{\star 2}$} \\
\hline$\leq 1.5$ & $89(77.4)$ \\
\hline$>1.5$ & $26(22.6)$ \\
\hline \multicolumn{2}{|l|}{ Serum CYFRA $21-1(\mathrm{ng} / \mathrm{mL})^{\star 3}$} \\
\hline$\leq 3.5$ & $119(83.8)$ \\
\hline$>3.5$ & $23(16.2)$ \\
\hline \multicolumn{2}{|l|}{ ILDs on HRCT } \\
\hline Yes & $30(17.3)$ \\
\hline \multicolumn{2}{|l|}{$\% \mathrm{VC}$} \\
\hline$<80$ & $22(12.7)$ \\
\hline \multicolumn{2}{|l|}{$\mathrm{FEV}_{1.0} \%$} \\
\hline$<70$ & $71(41.0)$ \\
\hline \multicolumn{2}{|l|}{ Operation } \\
\hline Segmentectomy & $47(27.2)$ \\
\hline Lobectomy & 126 (72.8) \\
\hline
\end{tabular}

Table 3 (continued)
Table 3 (continued)

\begin{tabular}{lc}
\hline Characteristics & No. (\%) \\
\hline Pathological nodal involvement & \\
pN0 & $167(96.5)$ \\
pN1 & $4(2.3)$ \\
pN2 & $2(1.2)$
\end{tabular}

Pathological stage

IA

$143(82.7)$

IB

25 (14.5)

IIA

IIIA

Visceral pleural invasion

PLO

$148(85.5)$

PL1

23 (13.3)

PL2

$2(1.2)$

Lymphatic invasion

Ly0

$110(63.6)$

Ly1

63 (36.4)

Vascular invasion

vo

$115(66.5)$

V1

$52(30.1)$

V2 6 (3.4)

${ }^{* 1}$, serum CEA was measured in 156 patients; *2 , serum SCCAg was measured in 115 patients; ${ }^{* 3}$, serum CYFRA 21-1 was measured in 142 patients; CEA, carcinoembryonic antigen; SCC-Ag, squamous cell carcinoma antigen; CYFRA 21-1, cytokeratin-19 fragments; ILD, interstitial lung disease; HRCT, high-resolution computed tomography.

recently reported that COPD had no impact on the mortality of smokers with NSCLC. We surmise that among the patients we analyzed, of whom more than $97 \%$ had a history of smoking and more than $40 \%$ had obstructive pulmonary disease, the prognostic impact of COPD would be weakened.

Increased serum levels of tumor markers can be indicators of worse outcomes. In the published literature, high serum levels of CEA (29) and SCC-Ag (9,30) have been found to indicate poor outcomes in patients with early-stage lung SqCC. We also found that a high serum SCC-Ag level was an independent risk factor for 


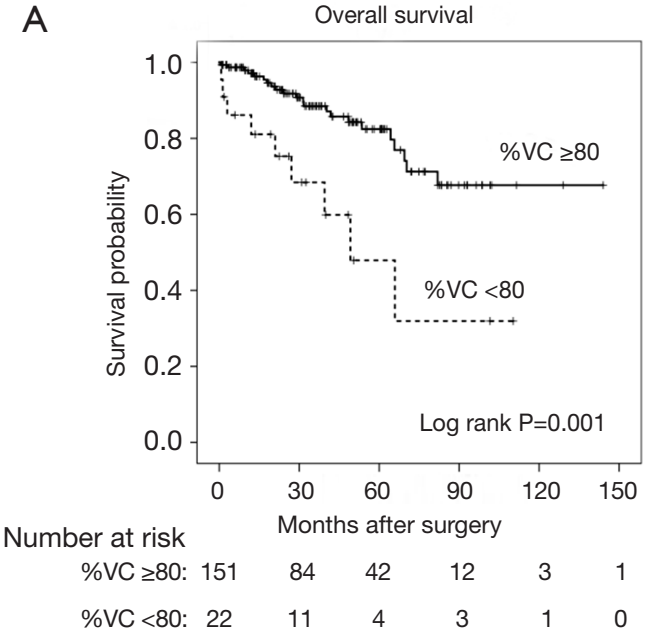

Figure 1 Kaplan-Meier estimates for overall (A) and relapse-free (B) survival by \%VC in patients who received anatomical lung resection $(n=173)$.

recurrence after anatomical resection; however, a major limitation of this study was that the serum SCC-Ag level was only measured in $150(67.6 \%)$ of all 222 study patients, and 115 (66.5\%) of 173 patients who underwent anatomical resection. The low serum SCC-Ag assessment rate might have been due to the fact that preoperative histological confirmation of lung SqCC was not always performed for these small tumors, and therefore tumor markers were not always assessed. The low assessment rate of serum SCC-Ag level might lead to biased results. Therefore, the prognostic impact of increased serum SCC-Ag in this study should be considered with caution. In addition, we note that coexisting pulmonary diseases such as idiopathic pulmonary fibrosis (31) can lead to increased serum SCC-Ag levels.

Patients with cT1aN0M0 peripheral SqCC of the lung can be candidates for segmentectomy, either intentional or passive. In order to reduce the postoperative risk for local recurrence, the preoperative risk factors for local recurrence after segmentectomy for NSCLC have been studied and identified (32-34). To date, positive tumor margins, visceral pleural involvement, lymphatic invasion, vascular invasion, and tumor grade have been identified as risk factors for local recurrence $(33,35)$. In patients with SqCC of the lung, visceral pleural invasion (30), lymphatic invasion (36) and vascular invasion $(9,30)$ have been found to be risk factors for poor outcomes in several studies that did not assess the effects of pulmonary function parameters in detail. In our study, visceral pleural invasion and lymphatic invasion were not found to be significantly prognostic, although they

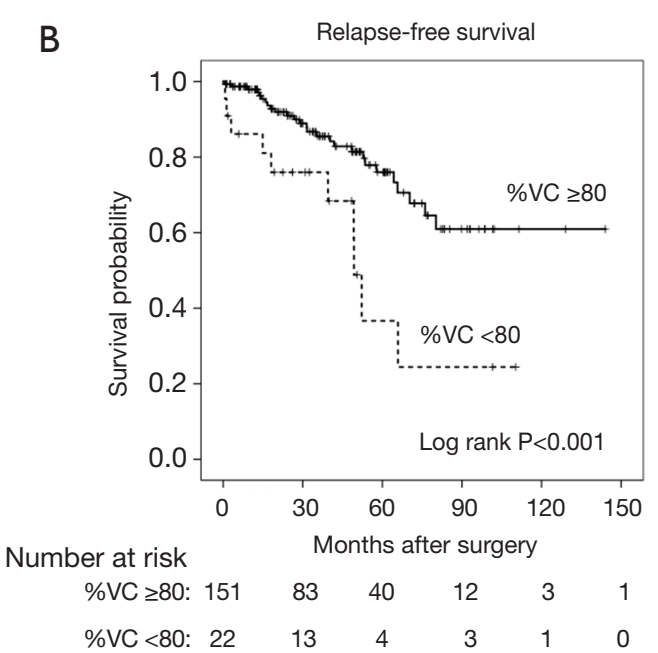
.

tended to show worse outcomes. In addition, the presence of vascular invasion did not appear to affect survival in our study. These conflicting study results on the prognostic effects of lymphatic and vascular invasion suggest that their prognostic effects remain unclear. The differences also indicate that accurate identification of these features may be difficult even when employing specific materials such as D2-40. The histopathological criteria for definitively identifying these factors require additional study.

Local recurrence after anatomical resection was seen in 5 (2.9\%) of 173 study patients during a median-follow up period of 32.6 months. When limited to segmentectomy, local recurrence developed in 2 (4.3\%) of 47 patients. Three of the 5 patients in whom pathological nodal involvement was absent, developed lymph node metastasis. Tsutani et al. (36) found that metastasis to locoregional or distant lymph nodes could occur in patients with pathological stage I lung SqCCs after anatomical resection combined with systematic lymphadenectomy. A multicenter phase III trial (JCOG0802/WJOG4607L) that compares segmentectomy with lobectomy for patients with cT1aN0M0 peripheral NSCLC (37), which is now ongoing in Japan, should provide new information about this issue.

We note that peripheral small lung SqCCs, even solitary tumors, can be metastatic. In this study, we excluded patients with a past history of possible SqCC, such as head and neck cancers, and those patients who died of such cancers. Nevertheless, we cannot completely discard the possibility that we included patients with subclinical SqCC of another organ that metastasized to the lung, which is 
Table 4 Outcome of patients undergoing anatomical resection $(n=173)$

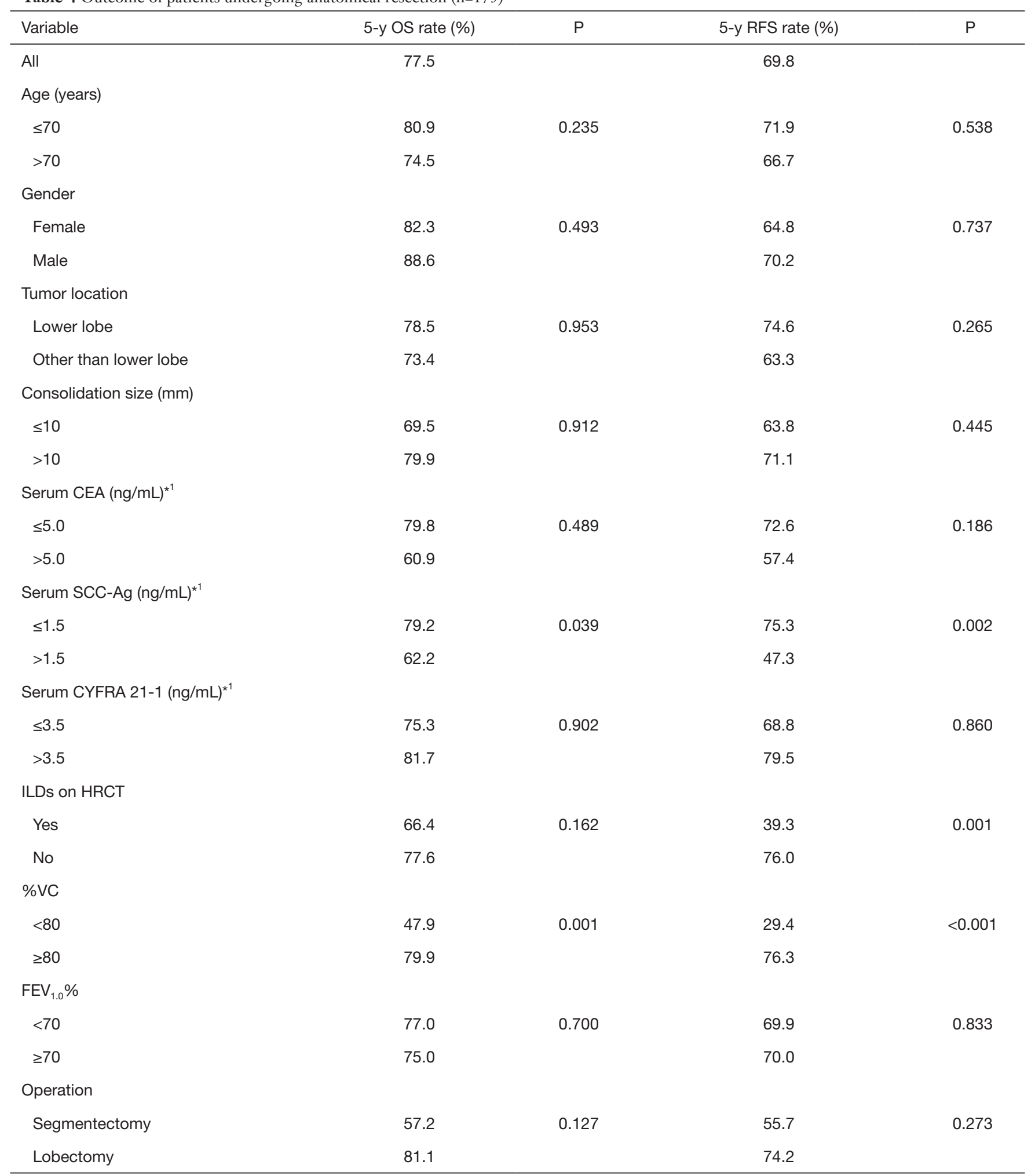

Table 4 (continued) 
Table 4 (continued)

\begin{tabular}{|c|c|c|c|c|}
\hline Variable & 5-y OS rate (\%) & $\mathrm{P}$ & 5-y RFS rate (\%) & $\mathrm{P}$ \\
\hline Negative & 75.5 & 0.708 & 70.0 & 0.481 \\
\hline Positive & 83.3 & & 66.7 & \\
\hline \multicolumn{5}{|c|}{ Pathological stage } \\
\hline Other than IA & 65.0 & & 54.9 & \\
\hline \multicolumn{5}{|c|}{ Visceral pleural invasion } \\
\hline Negative & 77.0 & 0.303 & 71.9 & 0.267 \\
\hline Positive & 68.5 & & 57.3 & \\
\hline Positive & 67.8 & & 63.0 & \\
\hline \multicolumn{5}{|l|}{ Vascular invasion } \\
\hline Negative & 73.8 & 0.525 & 67.2 & 0.276 \\
\hline Positive & 79.4 & & 75.0 & \\
\hline
\end{tabular}

${ }^{* 1}$, missing values were imputed using expectation-maximization algorithm; CEA, carcinoembryonic antigen; SCC-Ag, squamous cell carcinoma antigen; CYFRA 21-1, cytokeratin-19 fragments; ILD, interstitial lung disease; HRCT, high-resolution computed tomography; VC, vital capacity; FEV $_{1.0}$, forced expiratory volume in $1 \mathrm{~s}$; OS, overall survival; RFS, relapse-free survival.

Table 5 Multivariate analysis for survival ( $\mathrm{n}=173)$

\begin{tabular}{lccccc}
\hline \multirow{2}{*}{ Risk factor } & \multicolumn{2}{c}{ OS } & & RFS \\
\cline { 2 - 5 } & $\mathrm{HR}(95 \% \mathrm{Cl})$ & $\mathrm{P}$ & $\mathrm{HR}(95 \% \mathrm{Cl})$ & $\mathrm{P}$ \\
\hline SCC-Ag high & - & - & $1.60(1.12-2.29)$ & 0.004 \\
ILDs on HRCT & - & 0.002 & $2.97(1.44-6.10)$ & 0.009 \\
\%VC $<80$ & $3.29(1.52-7.09)$ & 0.003 & \\
\hline
\end{tabular}

$\mathrm{HR}$, hazard ratio; Cl, confidence interval; SCC-Ag, squamous cell carcinoma antigen; ILD, interstitial lung disease; HRCT, high-resolution computed tomography; VC, vital capacity; OS, overall survival; RFS, relapse-free survival.

another limitation of this study.

In conclusion, the coexistence of restrictive ventilatory impairment was an independent risk factor for both poor OS and RFS in patients with cT1aNOM0 peripheral SqCC of the lung. Lobectomy, if possible, should offer better outcomes for patients with such tumors. The coexistence of restrictive rather than obstructive pulmonary disease in patients with cT1aN0M0 peripheral lung SqCC should be taken into account during surgical planning.

\section{Acknowledgements}

None.

\section{Footnote}

Conflicts of Interest: The authors have no conflicts of interest to declare.

Ethical Statement: This study was approved by the ethics board of Okayama University Hospital (approval number: 1054), 
in which all the data was collected. Data collection and analysis was approved by the ethics board of each institution.

\section{References}

1. National Lung Screening Trial Research Team, Aberle DR, Adams AM, et al. Reduced lung-cancer mortality with low-dose computed tomographic screening. N Engl J Med 2011;365:395-409.

2. Rami-Porta R, Ball D, Crowley J, et al. The IASLC Lung Cancer Staging Project: proposals for the revision of the $\mathrm{T}$ descriptors in the forthcoming (seventh) edition of the TNM classification for lung cancer. J Thorac Oncol 2007;2:593-602.

3. El-Sherif A, Gooding WE, Santos R, et al. Outcomes of sublobar resection versus lobectomy for stage I non-small cell lung cancer: a 13-year analysis. Ann Thorac Surg 2006;82:408-15; discussion 415-6.

4. Tsutani Y, Miyata Y, Nakayama H, et al. Oncologic outcomes of segmentectomy compared with lobectomy for clinical stage IA lung adenocarcinoma: propensity score-matched analysis in a multicenter study. J Thorac Cardiovasc Surg 2013;146:358-64.

5. Yano M, Yoshida J, Koike T, Kameyama K, Shimamoto A, Nishio W, et al. Survival of 1737 lobectomy-tolerable patients who underwent limited resection for cStage IA non-small-cell lung cancer. Eur J Cardiothorac Surg 2015;47:135-42.

6. Koike T, Yamato Y, Yoshiya K, et al. Intentional limited pulmonary resection for peripheral T1 N0 M0 small-sized lung cancer. J Thorac Cardiovasc Surg 2003;125:924-8.

7. Okada M, Koike T, Higashiyama M, et al. Radical sublobar resection for small-sized non-small cell lung cancer: a multicenter study. J Thorac Cardiovasc Surg 2006;132:769-75.

8. Kawase A, Yoshida J, Ishii G, et al. Differences between squamous cell carcinoma and adenocarcinoma of the lung: are adenocarcinoma and squamous cell carcinoma prognostically equal? Jpn J Clin Oncol 2012;42:189-95.

9. Kinoshita T, Ohtsuka T, Yotsukura M, et al. Prognostic impact of preoperative tumor marker levels and lymphovascular invasion in pathological stage I adenocarcinoma and squamous cell carcinoma of the lung. J Thorac Oncol 2015;10:619-28.

10. Asamura H, Nakayama H, Kondo H, et al. Lymph node involvement, recurrence, and prognosis in resected small, peripheral, non-small-cell lung carcinomas: are these carcinomas candidates for video-assisted lobectomy? J

Thorac Cardiovasc Surg 1996;111:1125-34.

11. Funai K, Yokose T, Ishii G, et al. Clinicopathologic characteristics of peripheral squamous cell carcinoma of the lung. Am J Surg Pathol 2003;27:978-84.

12. Matsumura Y, Hishida T, Yoshida J, et al. Reasonable extent of lymph node dissection in intentional segmentectomy for small-sized peripheral non-smallcell lung cancer: from the clinicopathological findings of patients who underwent lobectomy with systematic lymph node dissection. J Thorac Oncol 2012;7:1691-7.

13. Koike T, Kitahara A, Sato S, et al. Lobectomy versus segmentectomy in radiologically pure solid smallsized non-small cell lung cancer. Ann Thorac Surg 2016;101:1354-60.

14. Ueda K, Jinbo M, Li TS, et al. Computed tomographydiagnosed emphysema, not airway obstruction, is associated with the prognostic outcome of early-stage lung cancer. Clin Cancer Res 2006;12:6730-6.

15. Turner MC, Chen Y, Krewski D, et al. Chronic obstructive pulmonary disease is associated with lung cancer mortality in a prospective study of never smokers. Am J Respir Crit Care Med 2007;176:285-90.

16. Alberg AJ, Brock MV, Samet JM. Epidemiology of lung cancer: looking to the future. J Clin Oncol 2005;23:3175-85.

17. Hubbard R, Venn A, Lewis S, et al. Lung cancer and cryptogenic fibrosing alveolitis. A population-based cohort study. Am J Respir Crit Care Med 2000;161:5-8.

18. Harris JM, Johnston ID, Rudd R, et al. Cryptogenic fibrosing alveolitis and lung cancer: the BTS study. Thorax 2010;65:70-6.

19. Hashimoto N, Iwano S, Kawaguchi K, et al. Impact of thin-section computed tomography-determined combined pulmonary fibrosis and emphysema on outcomes among patients with resected lung cancer. Ann Thorac Surg 2016;102:440-7.

20. Sato T, Teramukai S, Kondo H, et al. Impact and predictors of acute exacerbation of interstitial lung diseases after pulmonary resection for lung cancer. J Thorac Cardiovasc Surg 2014;147:1604-1611.e3.

21. Zwirewich CV, Vedal S, Miller RR, et al. Solitary pulmonary nodule: high-resolution CT and radiologicpathologic correlation. Radiology 1991;179:469-76.

22. Raghu G, Collard HR, Egan JJ, et al. An official ATS/ ERS/JRS/ALAT statement: idiopathic pulmonary fibrosis: evidence-based guidelines for diagnosis and management. Am J Respir Crit Care Med 2011;183:788-824.

23. Veluswamy RR, Ezer N, Mhango G, et al. Limited 
resection versus lobectomy for older patients with earlystage lung cancer: impact of histology. J Clin Oncol 2015;33:3447-53.

24. Tomassetti S, Gurioli C, Ryu JH, et al. The impact of lung cancer on survival of idiopathic pulmonary fibrosis. Chest 2015;147:157-64.

25. Sekine Y, Sakairi Y, Yoshino M, et al. The impact of combined pulmonary fibrosis and chronic obstructive pulmonary disease on long-term survival after lung cancer surgery. Thorac Cardiovasc Surg 2014;62:332-7.

26. Sato T, Watanabe A, Kondo H, et al. Long-term results and predictors of survival after surgical resection of patients with lung cancer and interstitial lung diseases. J Thorac Cardiovasc Surg 2015;149:64-9, 70.e1-2.

27. Gao YH, Guan WJ, Liu Q, et al. Impact of COPD and emphysema on survival of patients with lung cancer: A meta-analysis of observational studies. Respirology 2016;21:269-79.

28. Lee SJ, Lee J, Park YS, et al. Impact of chronic obstructive pulmonary disease on the mortality of patients with nonsmall-cell lung cancer. J Thorac Oncol 2014;9:812-7.

29. Nagashima T, Sakao Y, Mun M, et al. A clinicopathological study of resected small-sized squamous cell carcinomas of the peripheral lung: prognostic significance of serum carcinoembryonic antigen levels. Ann Thorac Cardiovasc Surg 2013;19:351-7.

30. Kinoshita T, Ohtsuka T, Hato T, et al. Prognostic factors based on clinicopathological data among the patients with resected peripheral squamous cell carcinomas of the lung.

Cite this article as: Tao H, Soh J, Yamamoto H, Fujiwara T, Ueno T, Hayama M, Okazaki M, Sugimoto R, Yamashita M, Sano Y, Okabe K, Matsuura M, Kataoka K, Moriyama S, Toyooka S, Miyoshi S. Restrictive ventilatory impairment is associated with poor outcome in patients with cT1aN0M0 peripheral squamous cell carcinoma of the lung. J Thorac Dis 2017;9(11):4325-4335. doi: 10.21037/jtd.2017.10.70
J Thorac Oncol 2014;9:1779-87.

31. Calabrese F, Lunardi F, Giacometti C, et al. Overexpression of squamous cell carcinoma antigen in idiopathic pulmonary fibrosis: clinicopathological correlations. Thorax 2008;63:795-802.

32. Koike T, Koike T, Yamato Y, et al. Prognostic predictors in non-small cell lung cancer patients undergoing intentional segmentectomy. Ann Thorac Surg 2012;93:1788-94.

33. Koike T, Koike T, Yoshiya K, et al. Risk factor analysis of locoregional recurrence after sublobar resection in patients with clinical stage IA non-small cell lung cancer. J Thorac Cardiovasc Surg 2013;146:372-8.

34. Taylor MD, Nagji AS, Bhamidipati CM, et al. Tumor recurrence after complete resection for non-small cell lung cancer. Ann Thorac Surg 2012;93:1813-20; discussion 1820-1.

35. Varlotto JM, Medford-Davis LN, Recht A, et al. Identification of stage I non-small cell lung cancer patients at high risk for local recurrence following sublobar resection. Chest 2013;143:1365-77.

36. Tsutani Y, Miyata Y, Mimura T, et al. Prognostic impact of lymphatic invasion for pathological stage I squamous cell carcinoma of the lung. Gen Thorac Cardiovasc Surg 2015;63:153-8.

37. Nakamura K, Saji H, Nakajima R, et al. A phase III randomized trial of lobectomy versus limited resection for small-sized peripheral non-small cell lung cancer (JCOG0802/WJOG4607L). Jpn J Clin Oncol 2010;40:271-4. 